\title{
Cardiomyopathy syndrome in farmed Atlantic salmon Salmo salar: occurrence and direct financial losses for Norwegian aquaculture
}

\author{
E. Brun ${ }^{1, *}$, T. Poppe ${ }^{2}$, A. Skrudland ${ }^{3}$, J. Jarp ${ }^{1}$ \\ ${ }^{1}$ National Veterinary Institute, PO Box 8156 Dep., 0033 Oslo, Norway \\ ${ }^{2}$ Norwegian School of Veterinary Medicine, PO Box 8146 Dep., 0033 Oslo, Norway \\ ${ }^{3}$ Nordvest fiskehelse, Bruhagen, 6530 Averøy, Norway
}

\begin{abstract}
Cardiomyopathy syndrome (CMS) was first diagnosed in the mid-1980s in farmed Atlantic salmon in Norway, and later also in Scotland and the Faeroe Islands. In Norway the number of diagnosed cases increased from 25 to 103 in the period from 1998 to 2001 according to the National Veterinary Institute (NVI) records. Very little is known about the causes of the disease and there is no documentation of its impact on the farmed salmon industry. This field survey was performed to collect information on occurrence, risk factors and the economic importance of CMS in sea farmed Atlantic salmon Salmo salar in Norway. Data were collected in January 2001 from a total of 174 groups of farmed salmon which had been previously transferred to sea during 1999 and 2000. Approximately $11.5 \%$ of all groups of salmon in our study experienced cases of CMS. Affected fish were presumably in generally good condition prior to time of death. In fish which had completed the seawater production cycle, CMS occurred more than $1 \mathrm{yr}$ (median $395 \mathrm{~d},>2 \mathrm{~kg}$ body weight) after seawater transfer. In fish transferred into the sea during autumn 2000 which had not completed the seawater cycle during the study period, CMS was diagnosed at a weight as low as $700 \mathrm{~g}$. Although sudden death is characteristic, CMS may be regarded as a chronic disease, with moderately elevated mortality rates at site level. Affected groups showed significantly increased mortality, causing a direct annual financial loss for the industry of $€ 4.5$ to 8.8 million on fish farms. Preventive prescheduled slaughtering of salmon, which is performed on many affected farms, may be too costly when done too early.
\end{abstract}

KEY WORDS: Atlantic salmon $\cdot$ Cardiomyopathy syndrome $\cdot$ Financial losses

\section{INTRODUCTION}

The list of cardiac diseases in farmed salmon has been steadily increasing in recent years and includes infectious diseases, neoplasms, malformations, and combinations of these, as well as diseases of unknown causes. One of these diseases is cardiomyopathy syndrome (CMS). Gross lesions include cardiovascular breakdown and cardiac tamponade (haemopericardium) due to rupture of the atrium or sinus venosus. Histopathological changes are initially found in spongious myocardium of the atrium and ventricle. Degeneration and coagulation necrosis of myocardial fibres are pronounced, as well as infiltration by lymphocytes and macrophages (Ferguson 1989, Ferguson et al. 1990, Sande \& Poppe 1995).

CMS was first reported in farmed Atlantic salmon Salmo salar in Norway in the mid-1980s (Amin \& Trasti 1988, Ferguson et al. 1990) and later also from the Faeroe Islands and Scotland (Wood et al. 1995, Rodger \& Turnbull 2000, P. Østergård pers. comm.). Recently CMS has been diagnosed in wild Atlantic salmon and Chinook salmon Oncorhynchus tschawytscha in British Columbia, Canada (Poppe \& Ferguson unpubl.).

CMS is not a notifiable disease in Norway and there are no systematic records of its occurrence. However, annual reports and comments from field veterinary 
services indicate a steady increase in its frequency over the years. CMS traditionally manifests itself in salmon 12 to 18 mo after transfer to seawater, and affected fish frequently die without any prior clinical signs of disease (Amin \& Trasti 1988, Ferguson et al. 1990). Prior to death, they apparently grow according to a normal weight-gain curve, have a normal body condition, and at autopsy show normal gastrointestinal content with respect to amount and consistency. Although individuals experience sudden death, CMS appears most often like a chronic disease at site level, with a long-lasting, moderately elevated mortality rate, which may increase with stress (e.g. due to predators, superimposed diseases, grading, treatments and transportation). However, sometimes there is an acute, dramatic increase in mortality.

The cause of the disease is unknown. Genetic and metabolic and/or environmental conditions have been excluded (Vågnes et al. 1999), and theories involving pancreas disease (Ferguson et al. 1990, M. McLoughlin pers. comm.) and the presence of a nodavirus-like agent (Grotmol et al. 1997) have not been pursued further. Recent discoveries of CMS in wild salmon support the involvement of an infectious agent (Poppe \& Ferguson unpubl.). No decisive preventive measures are known, and there is no treatment available. Although premature slaughtering or reduced feeding is practised in an attempt to reduce losses, shortcomings in scientific knowledge leave the farmers with practically no alternatives to prevent the problem.

Few analyses of the economic consequences of fish diseases have been performed, and there is no literature describing the influence of CMS on the economic returns. Cataracts in farmed Atlantic salmon were estimated to cause an annual direct loss of $€ 27.9$ million for Norwegian farmers (Menzies et al. 2002). This is a chronic, non-treatable disease affecting weight gain and survival rates throughout the whole seawater phase (Ersdal et al. 2001). However, a disease like CMS, affecting fish late in the production cycle, has a serious economic impact because mortalities occur late in the life cycle when the expenditures incurred are high.

The main goal of this study was to focus on the significance of the disease in Norwegian aquaculture through documentation of: (1) its occurrence, (2) potential risk factors, and (3) financial consequences.

\section{MATERIALS AND METHODS}

The target population of the study was from Atlantic salmon sea farms in Norway. The study consisted of 2 separate parts: 'data-mining' of the diagnostic recording system at the National Veterinary Institute (NVI), and a questionnaire-based survey involving regional fish health services. Each fish farm has its own health supervising service or a contract with an outside service. The activities of these services include regular inspections of the sites, and visits in cases of acute disease outbreaks. The frequent contact with the production sites gives their staff a thorough knowledge of the disease situation in the farms.

Database management at the NVI. The NVI is a government institution with a total of 6 laboratories covering different regions in Norway. Traditionally, most fish health services have utilized the diagnostic competence of the NVI laboratories. As all the laboratories register diagnostic information in a common recording system and store it on a mutual database, NVI possesses historical and updated records of essential diagnostic information from the whole country. This database was searched for information on CMS from the years 1998 to 2001 .

Questionnaire survey. A questionnaire was sent by mail to a total of 23 services representing almost $100 \%$ of all fish health services and covering almost the entire target population of farmed salmon. The questionnaire was designed to collect routine data kept either by the services themselves or by the farms. The questionnaire aimed to cover historical data on fish transferred to sea during spring and autumn 1999 (99G-spring and 99G-autumn) and 2000 (00G-spring and 00G-autumn). All information was linked to a group unit defined as a fish stock resulting from one or more transfers to a specific site of fish sharing the same genetic background, age (1 or 0 yr), and origin (smolt supplier).

The questionnaire asked for information including the names of suppliers, the genetic origin of the smolt, the dates and number of fish transferred to a specific site, whether farms practiced separation or mixing of different generations (age groups) and species at a site, disease and treatment history in general, and specifically related to CMS, mortality data for salmon with and without CMS, and preventive measures taken.

A group was defined CMS positive if CMS was histopathologically diagnosed in one or more fish examined either by routine sampling or as a part of an outbreak investigation. An exact CMS diagnosis is difficult to make in the field, because several diseases resemble CMS and one cannot distinguish between them without laboratory examination. Consequently, the commonly used term CMS may include other diseases as well (Poppe \& Taksdal 1997). In order to increase the specificity of the response variable CMS, the services polled were especially asked about the criteria used for their diagnosis.

Mortality data were collected from registers at farms where dead fish are collected routinely and counted 
every 2 or 3 d during winter and every day during the summer season. Mortality was given on the questionnaire as a proportion of the initial group size at sea transfer, and transformed to its geometric mean in the statistical analysis to approximate the normal distribution criteria.

Statistical analysis. Descriptive and multivariate statistical analyses were performed in SAS-PC System version 6.12 for Windows (SAS Institute) using the procedures 'proc univariate', 'proc logistic' and 'proc glm'.

Economic model. A partial budget analysis was developed in Excel spreadsheet (Microsoft) including '@RISK: a risk analysis software add-on' (Palisade) using Latin hypercube sampling. This method facilitates the inclusion of uncertainty and variability in input variables. All calculations were done at the individual farm level on the basis of a transfer of 260000 fish (group size). Losses at an individual farm with CMS were compared to a similar farm not having CMS.

Information received from the health services was used for estimating mortality in the model. The average mortality through one production cycle was empirically distributed on monthly rates. A CMS outbreak was simulated at $2 \mathrm{~kg}$ causing a relative increase in mortality from this point onwards in affected groups. The mortality estimates used in the model were taken from the mortality estimates calculated from the field study.

The prices for fresh Norwegian salmon on the EU market were taken from www.intrafish.no. An official annual report on the profitability of salmon aquaculture at the farm level in Norway was used for information concerning feed prices, feed conversion rates, smolt weights and various costs (smolt price, insurance, labour and capital costs) (Anonymous 2001).

Growth rate was adjusted for season and anticipated water temperature according to a growth rate standard (Anonymous 1993). Monthly growth $\left(V^{\mathrm{n}}\right)$ was estimated by the formula $V_{\mathrm{n}}=V_{\mathrm{n}-1} \times(1+\mathrm{dwg})^{t}$, where $\mathrm{n}$ is a specific month, dwg = daily weight gain and $t=30 \mathrm{~d}$.

Feeding costs were linked to the biomass at any time, while capital costs, labour, and other various costs were linked to the number of fish initially transferred to sea, regardless of losses during the production time (considered fixed).

The economic cost of a disease is generally represented by the sum of losses and expenditures connected with the disease (McInerney et al. 1992). For CMS, no specific expenditures are defined, which makes costs equal to calculated loss. The direct loss was calculated as the difference in cumulative revenue (market value - total input) between healthy and CMS-affected groups.

Input values on feed conversion, feed cost and slaughter value were given a uniform @Risk distribution, while mortality was assumed to be normally dis- tributed. Monthly mortalities were put into the model individually, and assumed to be independent of one another (not linked).

\section{RESULTS}

A total of 246 cases of CMS were registered during the 4 yr period from 1998 to 2001 in the database kept by the NVI. Of these cases, 25 were diagnosed in 1998, increasing to 103 cases in 2001 and 101 in 2002 . We do not have any denominator in this material to calculate the proportional increase in CMS to the increase in salmon production. However, sales figures for slaughtered salmon only showed a $20 \%$ increase (from 361000 to 438000 ) during the given time period (Anonymous 2002). By 1998 CMS had been diagnosed all along the coast and there was no obvious change in the distribution pattern during our 4 yr study. Most samples of materials diagnosed as CMS positive were submitted to the NVI during the spring and autumn (Fig. 1).

Of the surveyed health services, $39 \%$ responded to the questionnaire. They served ca. $32 \%$ of the total number of farms with licences for salmon and rainbow trout Oncorhynchus mykiss production, representing 174 different groups (number of licences given by The Norwegian Fish Farmers Association). The average group size was 263000 fish, with a range of 10700 to 1109273 . Assuming an equal distribution of groups per license, the total number of groups in the target population would be approximately 544 .

The occurrence of CMS at the group level was 14.6 (99G-spring), 13.3 (99G-autumn), 9.8 (00G-spring) and $8.6 \%$ (00G-autumn). All stock from 99G had been harvested by the time of data collection, while most of $00 \mathrm{G}$ was still in growout. CMS was verified by histopathological examination in $90 \%$ of the cases. A wide geographical distribution of cases was reported. No case was reported during July/August, and only 3 cases were reported from December to February. All other cases were reported from March to June (10 cases) and September to November (5 cases).

The average number of days from sea transfer to first diagnosis of CMS within the group was $410 \mathrm{~d}$ (median = 395.5), with a minimum of 253 and a maximum of $595 \mathrm{~d}$ post sea-transfer. This late onset of disease is reflected by the average weight of the affected group at the time of diagnosis, as shown in Table 1.

In addition to CMS, a list of other potential causes of increased mortality and stressful conditions were registered during the time at sea (Table 2). These were all evenly distributed among CMS positive and negative groups, except for outbreaks of infectious pancreatic necrosis (IPN). A previous outbreak of IPN was, on average, 4 times (odds ratio $(\mathrm{OR})=4.1$; confidence 


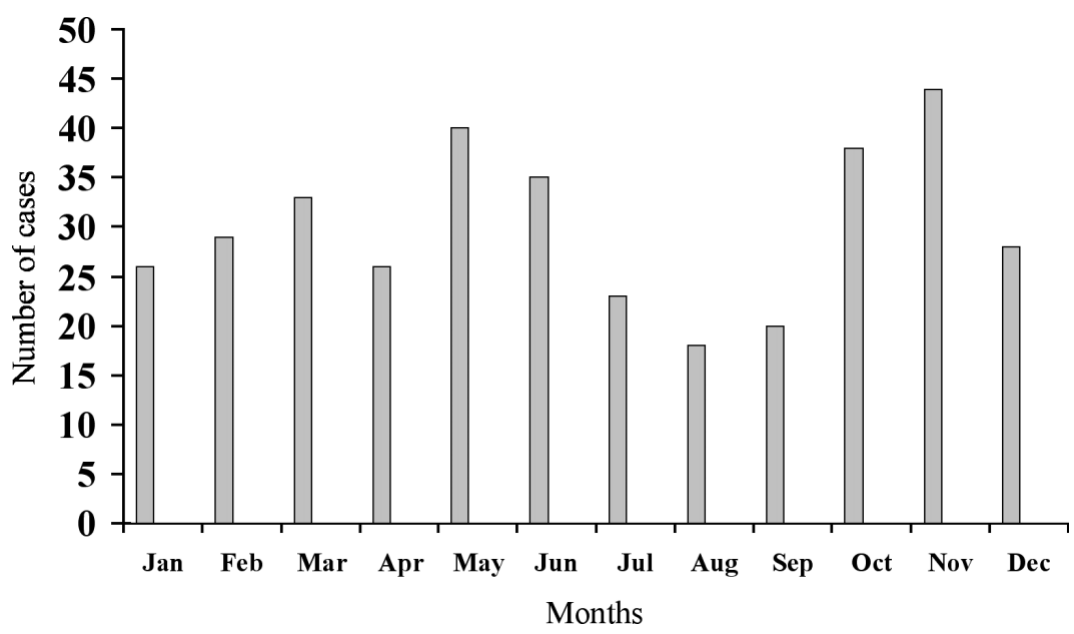

Fig. 1. Salmo salar. Monthly number of cases of cardiomyopathy syndrome in farmed Atlantic salmon based on field samples from 1998 to 2001

group of NOK 0.45 to 0.88 million (€60000 to 117000 ) (Fig. 2). If $14 \%$ of all groups in the target population experience CMS, the total annual direct loss due to this disease may be estimated at NOK 33.5 to 66.3 million (€ 4.6 to 8.3 million).

Keeping the variables constant, a 4 mo pre-scheduled slaughtering of 10 or $15 \%$ of the fish, due to CMS, increases the average group loss to 0.9 (0.8 to 1.0 within $90 \%$ ) and 1.4 (1.3 to 1.6 within $90 \%$ ) million NOK (€120000 and 187000$)$, respectively. The model indicates a break-even point or a reduction in loss when slaughtering occurs 3 and 2 mo pre-scheduled, respectively.

The influence of the various input variables on the final economic result

interval $(\mathrm{CI})=1.6$ to 10.4 ) more common among CMS groups than among those with no experience of CMS $\left(\chi^{2}=8.9 ; p=0.003\right)$. As one specific broodstock was very dominant in this material, information on genetic background was not suitable for statistical evaluation.

The results shown in Table 3 indicate that CMS causes a significant increase in mortality compared to non-CMS groups when statistically adjusted for alternative or additional causes of death (Table 2). The overall increase in mortality was independent of the time of outbreak.

In $59 \%$ of CMS-groups, CMS was assumed by farmers to be the specific cause of more than $70 \%$ of the total mortality.

\section{Economic evaluation}

The average body weight was estimated to increase from $0.07 \mathrm{~kg}$ at sea transfer in May, to a final weight of $5.1 \mathrm{~kg} 19$ mo later. The theoretical production cost was set at 16.5 Norwegian Kroner (NOK) $\mathrm{kg}^{-1}\left(€ 2.2 \mathrm{~kg}^{-1}\right.$ ).

An outbreak of CMS in groups of $260000 \times 2 \mathrm{~kg}$ salmon inflicts, for $90 \%$ of all cases, a direct loss per

Table 1. Salmo salar. Weight $(\mathrm{kg})$ in seawater-reared groups of Atlantic salmon when cardiomyopathy syndrome was first diagnosed in the group

\begin{tabular}{|llcc|}
\hline Sea transfer & Median & Minimum & Maximum \\
\hline Spring 1999 & 2.2 & 1.5 & $10^{\mathrm{a}}$ \\
Autumn 1999 & 2.95 & 1.5 & 5 \\
Spring 2000 & 3 & 2.2 & 5.3 \\
Autumn 2000 & 0.7 & 0.7 & 1.0 \\
a Broodstock & & & \\
\hline
\end{tabular}

(output), given as correlation coefficients between actual input and the output, was tested using a Tornado sensitivity analysis. Mortality and price $\mathrm{kg}^{-1}$ of the slaughtered fish were the only influential variables. Mortality was the most important variable with respect to time for scheduled slaughtering (Fig. 3A), while price $\mathrm{kg}^{-1}$ became more influential when proportions of pre-slaughtering varied (Fig. 3B,C).

\section{DISCUSSION}

This study demonstrates that CMS has a substantial economic impact on Norwegian fish farming. Available

Table 2. Salmo salar. Number of groups in which diseases other than cardiomyopathy syndrome (CMS) were diagnosed and to which increased mortality was ascribed

\begin{tabular}{|c|c|c|}
\hline \multirow[t]{2}{*}{ Disease } & \multicolumn{2}{|c|}{ Increased mortality } \\
\hline & No & Yes \\
\hline Pancreatic necrosis & 113 & 61 \\
\hline Infectious salmon anaemia & 174 & 0 \\
\hline Epitheliocystis $^{\mathrm{a}}$ & 132 & 12 \\
\hline Incomplete smoltification & 168 & 6 \\
\hline Algae blooms & 174 & 0 \\
\hline Jellyfish & 170 & 4 \\
\hline Predators & 152 & 20 \\
\hline Skin ulcers & 158 & 16 \\
\hline Heart muscle inflammation & 172 & 2 \\
\hline Accidents & 172 & 2 \\
\hline Cataract & & $1^{\mathrm{b}}$ \\
\hline Piscirikettsia salmonis & & $1^{\mathrm{b}}$ \\
\hline \multicolumn{3}{|c|}{$\begin{array}{l}\text { aData not received from all } 174 \text { groups } \\
\text { bData not requested, but specifically noted by } 1 \text { health } \\
\text { service }\end{array}$} \\
\hline
\end{tabular}


Table 3. Salmo salar. Mortality given as the proportion of dead to the total number of Atlantic salmon for those groups initially transferred to sea during 1999, grouped as cardiomyopathy syndrome (CMS) -negative or -positive. All groups were followed from sea transfer to slaughter. $\mathrm{n}=$ no. of groups

\begin{tabular}{|lrccccc|}
\hline & $\mathrm{n}$ & $\begin{array}{c}\% \text { mortality } \\
\text { (geometri- } \\
\text { cal mean) }\end{array}$ & $\begin{array}{c}95 \% \\
\mathrm{CI}\end{array}$ & $\begin{array}{c}\text { Min. } \\
\%\end{array}$ & $\begin{array}{c}\text { Max. } \\
\%\end{array}$ & $\mathrm{p}$ \\
\hline CMS-negative & 44 & 2.5 & $2.4-2.6$ & 0.4 & 16.9 & 0.004 \\
CMS-positive & 9 & 6.1 & $5.1-7.2$ & 1.5 & 19.9 & 0.004 \\
\hline
\end{tabular}

A major expense in fish production is feed costs. In our model, the estimated overall feed consumption is closely linked to biomass, which effectively makes feeding costs decrease parallel to the monthly loss of fish. Feed intake and growth are calculated independently of whether CMS is diagnosed or not. This may not be the case in real life. Often reduced feeding of affected fish is used to diminish mortality, which may influ-

information supports the general understanding that the disease has increased in frequency during the last few years, and may be starting to affect younger fish. In the 1999 generation, $14 \%$ of the groups experienced clinical CMS from sea transfer to slaughter. The percentage was less for the 2000 generation, but still high considering this generation was still at sea, and within the $95 \%$ statistical time interval for disease onset when the data were collected.

The average loss in returns, for the whole industry at the farm level, was estimated to be ca. $€ 4$ to 8 million. This is based on estimated mortalities from the farm data collected.

The model treats the groups equally regarding mortality and costs prior to a CMS diagnosis. However, both weight gain and feed consumption may be negatively influenced prior to a clinical outbreak, thus resulting in an underestimation of the loss. So far, however, there are no indications that latent or 'subclinical' CMS reduces weight gain.

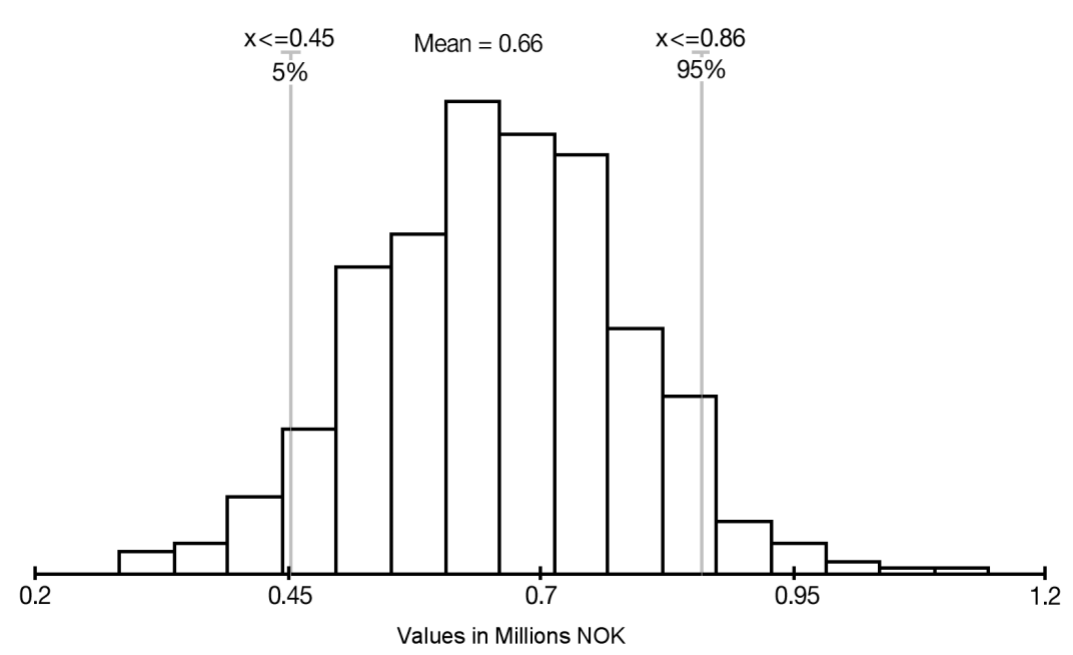

Fig. 2. Distribution of the direct financial loss at the farm level due to cardiomyopathy syndrome based on a sea transfer of 260000 Atlantic salmon Salmo salar smolts. Values in millions of Norwegian Kroner (NOK). (The $y$-axis is excluded from the graph, as the height of the curve [probability density] has no practical meaning. The $x$-value is a continuous variable and the probability of any specific value is 0 ; total area under the curve expresses a probability of 1 ) ence the link between feeding costs and growth.

Feed consumption may primarily be affected in 2 different ways: reduced feed intake (anorectic effect) and reduced feed conversion efficiency. Reduced feed intake may induce a temporary overfeeding, or more seriously, reduce the biological feed conversion. Although fish dying from CMS seem to perform and eat normally, the efficiency of feed conversion has not been evaluated. Maintenance of feed-intake simultaneously with a reduction in efficiency will generally reduce the production achieved from a defined amount of feed, and underestimate feeding costs in a farm with diseased fish.

Several farmers have tried to reduce losses by harvesting affected sub-groups prior to schedule. This is primarily done as a control measure to save not clinically diseased fish for consumption and to reduce further losses. The model indicates, however, that if this has to be done too early, even if the fish are slaughtered for market, it may have negative economic effects. The time of pre-slaughtering is not necessarily freely chosen, and this common practice could mean that the calculated loss in our model is an underestimation. The calculations in the model are based on a complete normalization of mortality in remaining fish after pre-slaughtering (a 100\% effective measurement), and pre-slaughtered fish achieving the same price per kilo at any size above 1 $\mathrm{kg}$. Although the figures are somewhat theoretical, the result emphasizes the advantage of evaluating the market situation, biomass and values involved prior to pre-slaughtering. This precaution is supported by the sensitivity analysis that shows that the most influential input for economically successful pre-slaughtering is the price achieved per kilo. The regulation of production through feeding quotas is not included in these estimations, but may obviously influence the conclusions.

Also not included in the economic model is the effect of pre-slaughtering 
A

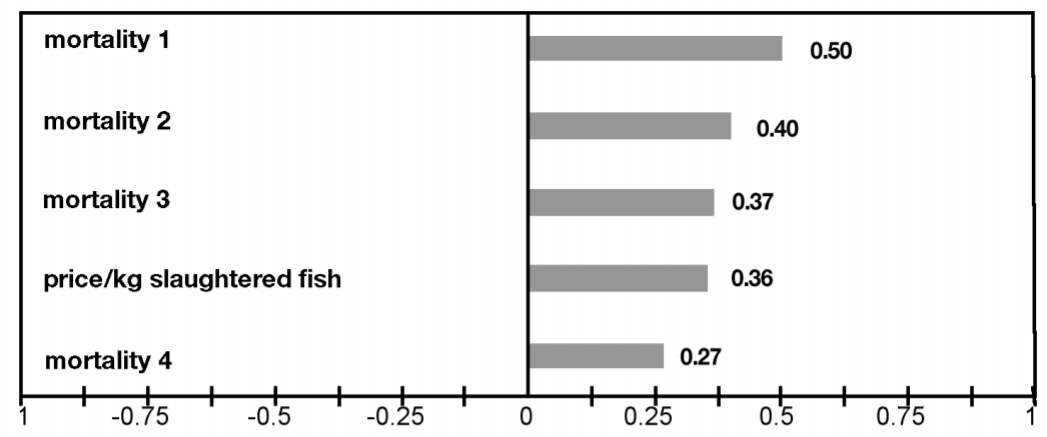

B

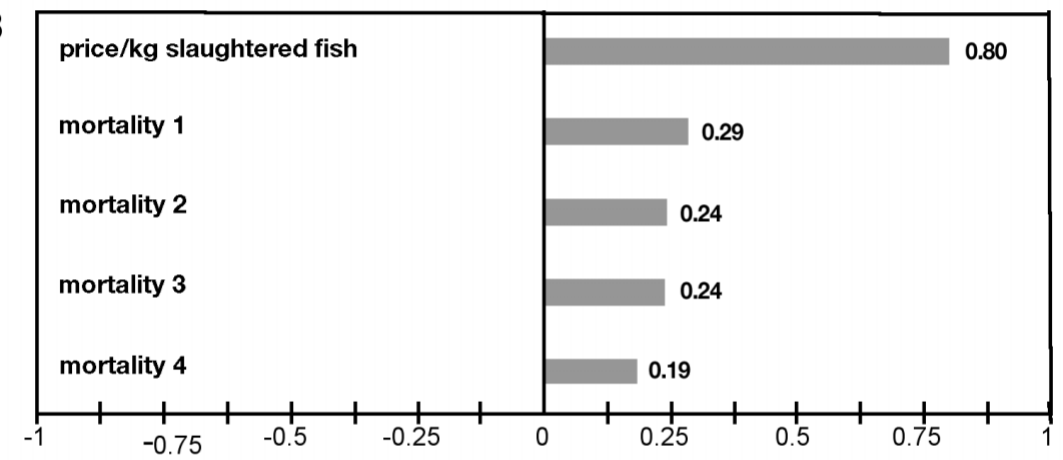

C

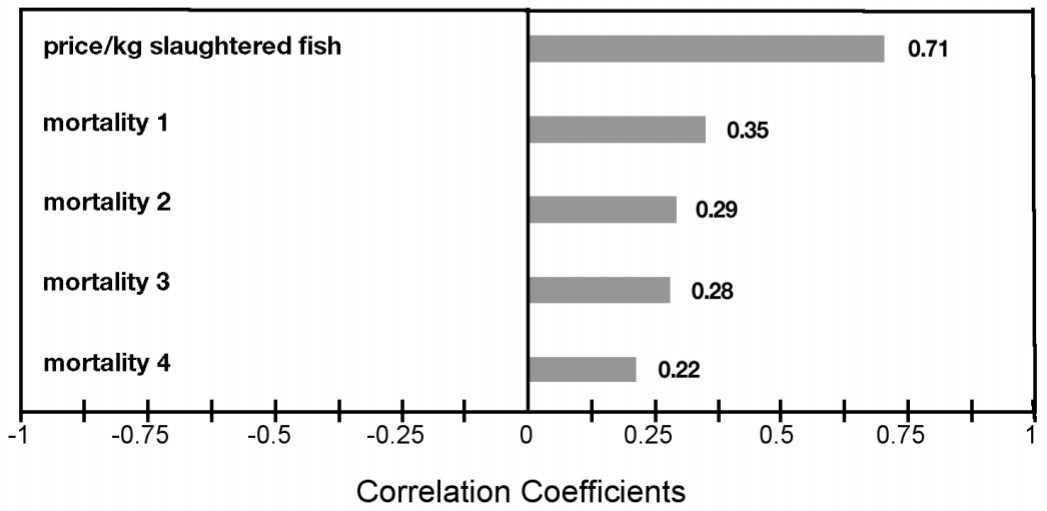

Fig. 3. Tornado graphs showing the most influential variables (price NOK kg${ }^{-1}$ slaughtered Atlantic salmon Salmo salar and monthly mortality prior to harvesting) affecting revenue when scheduled and pre-scheduled slaughtering due to cardiomyopathy syndrome (CMS) is performed. Mortality $1-4$ : mortality 1 to 4 mo prior to harvest. (A) No pre-schedule slaughtering; all fish are slaughtered at the scheduled time. (B) $15 \%$ of the diseased fish are harvested 3 mo prior to schedule to normalize the CMS situation. (C) $10 \%$ of diseased fish are harvested 3 mo prior to schedule to normalize the CMS situation

22 NOK ( $€ 2.4$ and 2.9), independent of size or time of year. According to Asche \& Guttormsen (2001), there is a cyclic regularity in relative salmon prices, and though different sizes may be equally priced, small salmon may reach top prices at a different time of year than larger salmon. Hence, the calculated losses may depend on the season for the disease outbreak occurs, and when major mortalities occur.

Data collection was considered laborious by the health services, especially in farms where CMS had been diagnosed. This may have meant that services serving farms with little or no CMS problems were more likely to participate in our survey than services with vast problems in their areas of operation. Personal contact with some of the non-participating indicate that the prevalence found in this study is an underestimation.

Records from the NVI show that CMS was diagnosed with an increasing frequency throughout the period 1998 to 2001. This may be the result of a greater awarenes among farmers and field veterinarians of the disease, and of improved diagnostic skills, but may also reflect a real increase in CMS problems. As the causes of CMS have not yet been determined and no protective measures specifically defined, a tendency towards increasing occurence should be of great concern. If CMS is shown to be infectious, then early slaughter will reduce the infection pressure at the site/inter-site level and probably become an influential positive economic variable in the current model.

The histopathological processes of CMS evolve slowly over time before the terminal stage is often revealed suddenly by some extraneous stress factors. This chronic expression of the dis-

on transmission of any infectious agent both within and between sites. It is difficult to assign monetary values to the beneficial effects of removing potentially infectious and diseased fish without more knowledge of the disease. However, their removal is a general hygienic measure aimed to reduce the frequency of infectious diseases.

In our model, prices of slaughtered fish are allowed to vary within a uniform distribution between 18 and ease indicates that the initial causes must be found at an earlier stage of life. There is a significant correlation between outbreaks of IPN and CMS. Although the confidence interval is wide and the lower limit is close to 1 , it indicates that CMS may be as much as 10 times more common in IPN fish than non-IPN fish. IPN is a very common disease in Norwegian farmed salmon (Melby et al. 1991). In human medicine, several different viruses are considered to be cardiotropic and it is 
assumed that more than $5 \%$ of a virally infected population experiences cardiac-related problems (Woodruff 1980, Rose et al. 1988, Kandolf \& Hofschneider 1989, Hofschneider et al. 1990) There is so far no evidence that IPN virus is, as such, a necessary cause of CMS, but the correlation indicates that CMS and IPN may have some common causes. IPN outbreaks may even be included in the causal pathway of the CMS pathogenesis. Both CMS and IPN are regarded as multifactorial diseases, manifesting themselves in parallel to increasing production intensity.

Our results showed an apparent seasonal variation in the occurrence of the disease. We have no explanation for this finding. However, spring and autumn are seasons when fluctuation in seawater quality are highest, which may create sudden extreme situations that susceptible individuals cannot adapt to. Variation in occurrence may also be artificial due to interruptions in normal sampling and laboratory routines during holidays and vacations.

The study has illustrated how death caused by CMS may affect revenues at the farm level, and how forced pre-slaughtering as a control measure may increase the financial loss. The association between outbreaks of CMS and IPN in seawater, and possibly other multifactorial diseases, should be followed up more closely to evaluate potential common risk factors to production-related infectious diseases.

Acknowledgements. We thank all health services that invested time to fill out and return our questionnaires, and to Dr. K. Christiansen for valuable criticism while preparing the manuscript. The study was supported by grants from the Norwegian Research Council.

\section{LITERATURE CITED}

Amin AB, Trasti J (1988) Endomyocarditis in Atlantic salmon in Norwegian sea farms. Bull Eur Assoc Fish Pathol 8:70-71 Anonymous (1993) Growth tables for farmed salmon. In: Gjerde $\mathrm{T}$ (ed) Aquaculture. A growing industry for rural Norway. Landbruksforlaget, Oslo (in Norwegian)

Anonymous (2001) Results from the profitability survey on Norwegian fish farms in 2000, Report 1/2001. The Directorate of Fisheries, Bergen (in Norwegian)

Anonymous (2002) Statistics for aquaculture 2001. The Directory of Fisheries, Bergen (in Norwegian)

Editorial responsibility: David Bruno,

Aberdeen, UK
Asche F, Guttormsen AG (2001) Patterns in the relative price for different sized farmed fish. In: Guttormsen AG (ed) Essays in aquaculture economics and management. Dr Sci thesis, Agricultural University of Norway, Às

Ersdal C, Midtlyng P, Jarp J (2001) An epidemiological study of cataracts in seawater farmed Atlantic salmon Salmo salar. Dis Aquat Org 45:229-236

Ferguson HW (1989) Systemic pathology of fish. Iowa State University, Ames, IA

Ferguson HW, Poppe T, Speare DJ (1990) Cardiomyopathy in farmed Norwegian salmon. Dis Aquat Org 8:225-231

Grotmol S, Totland GK, Kryvi H (1997) Detection of a nodavirus-like agent in heart tissue from reared Atlantic salmon Salmo salar suffering from cardiac myopathy syndrome (CMS). Dis Aquat Org 29:79-84

Hofschneider PA, Klingel K, Kandolf R (1990) Toward understanding the pathogenesis of enterovirus-induced cardiomyophatiy: molecular and ultrastructure approaches. J Struct Biol 104:32-37

Kandolf R, Hofschneider PH (1989) Viral heart disease. Spring Semin Immunopathol 11:1-13

McInerney JP, Howe KS, Schepers JA (1992) A framework for the economic analysis of disease in farmed livestock. Prev Vet Med 13:137 - 154

Melby HP, Krogsrud J, Håstein T, Stenwig H (1991) All commercial Atlantic salmon seawater farms in Norway harbour carriers of infectious pancreatic necrosis virus (IPNV). In: Fryer JL (ed) Proceedings 2nd International Symposium on Virus of Lower Vertebrates. Oregon State University, Corvallis, OR, p 211-217

Menzies FD, Crockford T, Breck O, Midtlyng PJ (2002) Estimation of direct costs associated with cataracts in farmed Atlantic salmon (Salmo salar). Bull Eur Assoc Fish Pathol 22:27-32

Poppe TT, Taksdal T (1997) Cardiac anomalies in farmed Atlantic salmon (Salmo salar L.). In: Abstracts 7th Int Conference on Diseases of Fish and Shellfish. European Association of Fish Pathologists, Edinburgh 14-19 September 1997

Sande RD, Poppe TT (1995) Diagnostic ultrasound end echocardiography in Atlantic salmon (Salmo salar). Vet Radiol Ultrasound 36:551-558

Rodger H, Turnbull T (2000) Cardiomyopathy syndrome in farmed Scottish salmon. Vet Rec 146:500-501

Vågnes $\varnothing$, Nylund A, Poppe T (1999) The cardiomyopathy syndrome. In: Poppe $\mathrm{T}$ (ed) Fish health and fish diseases. Universitetsforlaget, Oslo, p 153-154 (in Norwegian)

Wood BP, Bruno DW, Hastings TS (1995) Cardiomyopathy in farmed Atlantic salmon, Salmo salar. In: Abstracts 5th Int Conf on Diseases of Fish and Shellfish. European Association of Fish Pathologists, Palma de Mallorca, 10-15 September 1995

Woodruff J (1980) Viral myocarditis. A review. Am J Path 101: $427-482$

Submitted: March 6, 2003; Accepted: June 25, 2003

Proofs received from author(s): September 1, 2003 